\title{
Severe congenital nemaline myopathy with primary pulmonary lymphangiectasia: unusual clinical presentation and review of the literature
}

\author{
${\text { Jariya Waisayarat }{ }^{1 *} \text {, Chinnawut Suriyonplengsaeng }}^{1,3}$, Chaiyos Khongkhatithum ${ }^{2}$ and Mana Rochanawutanon ${ }^{1}$
}

\begin{abstract}
Introduction: Nemaline myopathy is a rare genetic muscle disorder defined by the presence of nemaline rods in the muscle fibre sarcoplasm. Congenital nemaline myopathy is the most serious form of the disease's spectrum.

Case presentation: The affected newborn has no spontaneous movement, fractures at birth and respiratory insufficiency. The present case was a Thai male, floppy at birth with fractures of both humeri and femurs and ventilator-dependent respiration. The patient developed bilateral chylothorax two weeks later and died at the age of 6 weeks. Whole-body postmortem examination with informed consent and genetic analysis of ACTA1 mutation were performed. A skeletal muscle biopsy examined by light and transmission electron microscopy showed the features of nemaline myopathy. ACTA 1 heterozygous missense mutation (c.1127G > C) was identified. Histological examination of both lungs revealed primary pulmonary lymphangiectasia.
\end{abstract}

Conclusion: To the best of our knowledge, congenital nemaline myopathy with primary pulmonary lymphangiectasia causing bilateral chylothrax has never been previously reported. Considering chylothorax as a poor prognostic index and an unusual clinical presentation of severe congenital NM are proposed.

Virtual Slides: The virtual slide(s) for this article can be found here: http://www.diagnosticpathology.diagnomx.eu/vs/ 9710506431489501.

Keywords: Severe congenital nemaline myopathy, Congenital myopathy, ACTA1, Chylothorax, Primary pulmonary lymphangiectasia

\section{Background}

The hallmark of all nemaline myopathies (NM), regardless of the genetic defect, is the presence of intrasarcoplasmic rod-like structures called nemaline bodies/rods which are stained red on the modified Gömöri trichrome preparation. This disorder was first recognized in 1963 by Shy and colleagues [1]. They proposed the term "nemaline myopathy" derived from the Greek word "nema" meaning thread. At the present time, NM is a well-recognized myopathy involving multiple genetic defects and encompassing a broad clinical spectrum varying from mild to severe muscle weakness. Affected patients are classified into six types based on the age at onset and the severity of motor

\footnotetext{
* Correspondence: jariya.wai@mahidol.ac.th

${ }^{1}$ Department of Pathology, Faculty of Medicine Ramathibodi Hospital, Mahidol University, Bangkok 10400, Thailand

Full list of author information is available at the end of the article
}

and respiratory involvement according to the classification of Wallgren-Pettersson and colleagues [2,3]. Congenital nemaline myopathy is the most serious form of the disease's spectrum. The affected newborn has no spontaneous movement, fractures at birth and respiratory insufficiency. Mutations in eight genes have now been identified in NM; ACTA1, NEB, TPM2, TPM3, TNNT1, CFL2, KBTBD13 and KLHL4O [4,5]. NM is listed as a "rare disease" by the Office of Rare Diseases of the National Institutes of Health. We present the postmortem examination of a case of congenital NM with the additional finding of bilateral chylothorax. Only two cases of severe congenital NM with chylothorax have been documented in the literature [6,7]. However, no cause of chylothorax was identified in both cases described in the literature. We discuss the possible mechanism of chylothorax in NM. Chylothorax is also a rare condition defined as the 
accumulation of chyle in the pleural space. Aetiologies of chylothorax can be mainly classified as traumatic or non traumatic [8]. Non traumatic causes are further subclassified as malignancy, diseases, congenital malformation or idiopathic. Moreover, congenital disorders and trauma due to intrathoracic surgery are responsible for the pathogenesis of neonatal chylothorax in most cases [9].

\section{Case presentation}

A male infant with generalized symmetrical hypotonia was born to non-consanguineous parents. The mother was a primigravida 22-year-old and the father was a healthy 28-year-old. Five older sisters and three older brothers of the maternal grandfather had died within the first year of life ranging from stillbirth to 7 months old without clarified cause of death. A cesarean section was carried out in the $37^{\text {th }}$ week of gestation because of breech presentation. Closed fractures of both humeri and femurs had occurred during delivery. Plaster casts were applied. The baby had absent spontaneous movement and difficult breathing. Apgar scores of 4 and 6 were documented at the $1^{\text {st }}$ and $5^{\text {th }}$ minutes, respectively. Eye movements were unimpaired. Intubation and ventilatory support were required. Weight, crown-heellength and head circumference were within normal limits (2,750 g, $47 \mathrm{~cm}$ and $37 \mathrm{~cm}$, respectively). Neurological deficits were observed; absent primitive reflexes (Moro, Babinski and grasping reflexes), loose anal sphincter tone and areflexia of all four limbs. Two weeks after birth, the patient developed bilateral pleural effusions (Figure 1) subsequently diagnosed as bilateral chylothorax due to the high triglyceride level $(4,773 \mathrm{mg} / \mathrm{dl})$ of the pleural fluid. No clinical evidence of heart failure was documented. Serum creatine kinase was normal (16 and $25 \mathrm{U} / \mathrm{L})$. Spinal muscular atrophy was excluded by analysis of the $S M N$ gene in which no mutations were

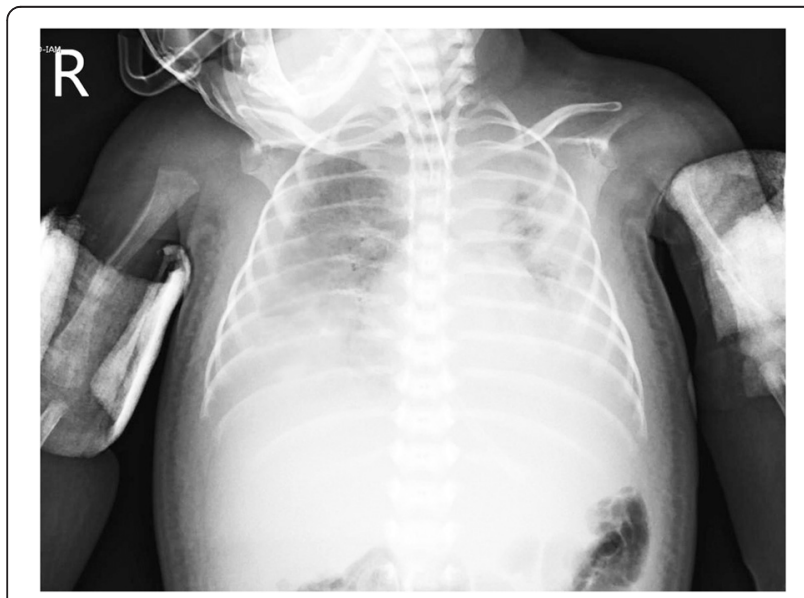

Figure 1 Chest radiograph demonstrated bilateral pleural effusion at 2 weeks of age. Closed fractures of both humeri were noted. found. Muscle biopsy from the right quadriceps femoris was performed at the age of 1 month. Despite the symptomatic treatment with ventilator support, intercostal drainage and parenteral nutrition, the patient still suffered from respiratory insufficiency and finally died at the age of 6 weeks. Informed consent for postmortem examination was formally obtained.

\section{Postmortem examination}

A high-arched palate and micrognathia were observed. Plaster casts of all fracture sites were noted. Generalized mild pitting oedema was present. Internal examination of the thoracic cavity revealed minimal milky fluid in both pleural cavities and severe pleural adhesions. The lung weight (60 g in total) and anatomy were normal. The thoracic duct rupture was not apparent. The cut surfaces of both lungs showed many dilated spaces measuring up to $0.2 \mathrm{~cm}$ in diameter. No structural cardiac anomaly was observed. Both testes were identified at the internal openings of the inguinal canals. Brain examination showed a normal external configuration with mild non-obstructive hydrocephalus revealed on slicing. Muscle samples from the biceps brachii, intercostal muscles, diaphragm and quadriceps femoris were obtained.

\section{Microscopic examination}

All muscle tissue obtained before and after death were preserved using a snap freezing technique. Frozen sections (10 microns) were cut and stained using a panel of tinctorial and enzyme histochemical methods according to standard protocols; haematoxylin and eosin (H\&E), modified Gömöri trichrome (mGt), nicotinamide adenine dinucleotide - tetrazolium reductase (NADH-TR), cytochrome oxidase (COX), succinate dehydrogenase (SDH), COX/SDH, periodic acid-Schiff (PAS), PAS with diastase (PASD), oil red $\mathrm{O}$, myophosphorylase, alkaline phosphatase, adenylate deaminase and ATPase at pH 4.3, 4.6 and 9.4.

Routine histology of the muscle demonstrated well populated fascicles and marked variation in muscle fibre size (4-40 micron). There were mild increase in internal nuclei (6\% of fibres), scattered atrophic and regenerating fibres, and moderate increase in endomysial and perimysial connective tissue. Split, whorled, necrotic and ragged red fibres were absent. Numerous nemaline rods were highlighted with mGt staining in almost type I fibres (Figure 2A). Transmission electron microscopy demonstrated copious sarcoplasmic electron dense nemaline rods (Figure 2B). Rods appeared either as extensions of sarcomeric Z-lines, in random array without obvious attachment to Z-lines, or in large clusters localized at the sarcolemma or intermyofibrillar spaces. The diagnosis of nemaline myopathy was established considering the clinical presentation and muscle pathology. Routine histology of the sampled tissue 

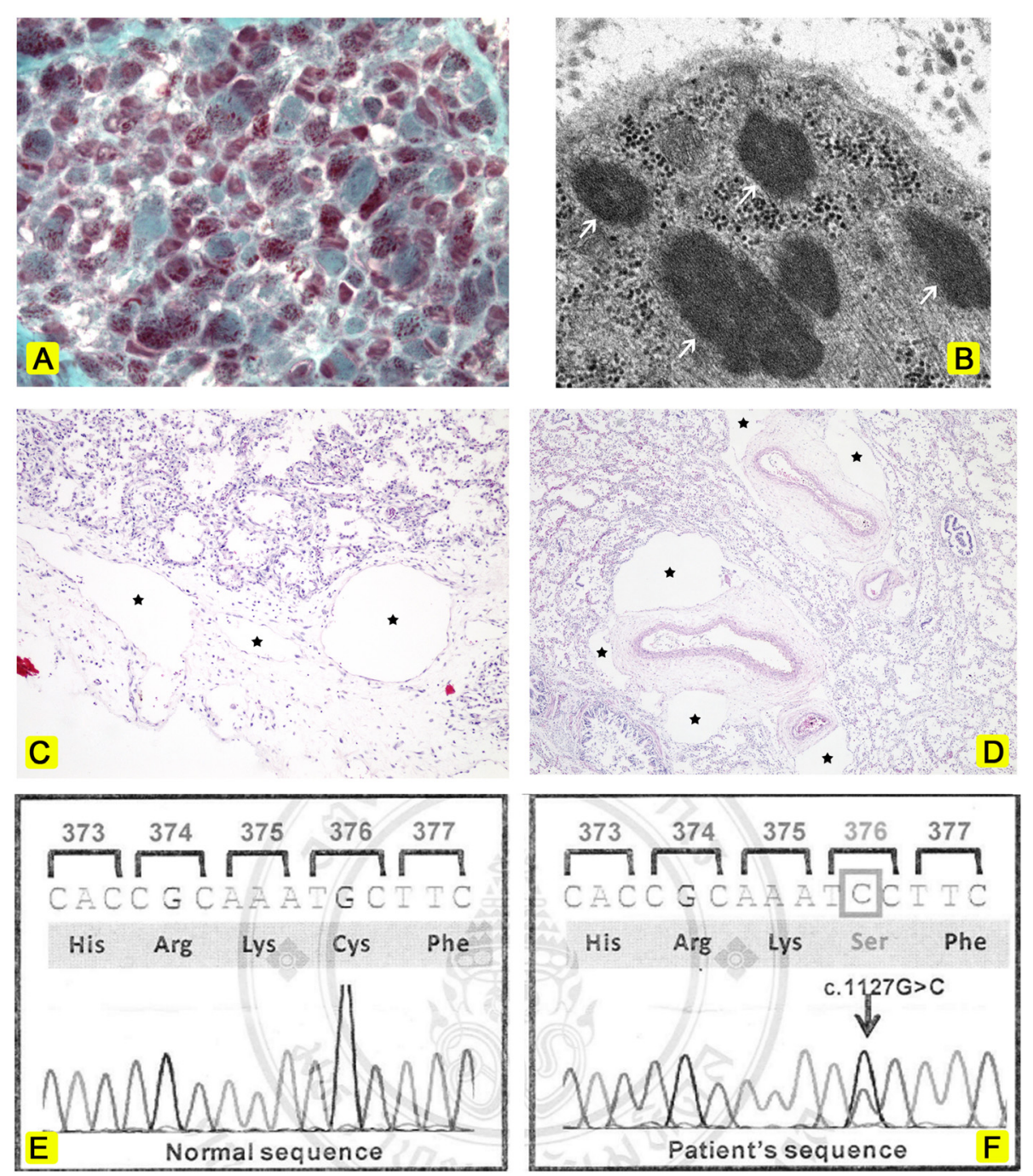

Figure 2 Summary of investigation. (A) The quadriceps femoris biopsy showed multiple red nemaline rods in sarcoplasm. mGt, X1000. (B) Electron micrograph revealed many nemaline rods (arrow) of uneven size. X30000. (C) Dilated lymphatic vessels (star) were noted in the pleura and interlobular septum. H\&E, X100. (D) Low power demonstrated markedly-dilated lymphatic vessels (star) in peribronchovascular areas. Some were more than 5 times of the adjacent alveolar diameter. H\&E, X40. (E) Normal sequence of the ACTA 1 gene (control). (F) A heterozygous substitution of $\mathrm{G}$ to $\mathrm{C}$ at nucleotide position 1127 (c.1127G > C) in exon 7 of ACTA1 gene was evident.

from each organ was performed. Microscopic examination of both lungs showed mature alveoli compatible with the alveolar stage of lung development. Diffuse dilatation of existing lymphatic vessels, without an increase in their number or complexity, were bilaterally evident in the subpleural connective tissue, interlobular septa and peribronchovascular areas (Figure 2C, D). The appearance was compatible with pulmonary lymphangiectasia rather than lymphangiomatosis. Positive immunoreactivity for CD31 and CD34 (low level) of the endothelial cells lining dilated lymphatic vessels was demonstrated. The hyaline membrane, a feature of diffuse alveolar damage, was absent. The CD31-and-CD34-immunoreactive endothelium of the dilated lymphatic vessels was also identified in the sections of pancreas. A choroid plexus papilloma $1 \mathrm{~cm}$ in diameter with features of a WHO grade I lesion was present in the left lateral ventricle giving rise to the documented communicating hydrocephalus.

\section{Genetic analysis}

ACTA1 gene analysis was performed on DNA derived from blood. Mutation analysis in 6 coding exons (exon 2-7) of ACTA1 gene was performed by PCR amplification, followed by direct DNA sequencing. A heterozygous substitution of $\mathrm{G}$ to $\mathrm{C}$ at nucleotide position 1127 (c.1127G > C) in exon 7 of $A C T A 1$ was identified, resulting in a Cys to Ser substitution at codon 376 (Cys376Ser) (Figure 2E,F). No ACTA1 mutation was evident in blood samples from either parent. 


\section{Discussion}

The ACTA1 gene locating on chromosome 1 (1q42.13) normally encodes skeletal muscle $\alpha$-actin protein, which is an essential component of sarcomeres in skeletal muscle fibres. Actin proteins are not only important for cell movement and muscle contraction, but also help maintaining the cytoskeleton determining cell shape and organizing cellular contents. Mutation of ACTA1 results in various types of congenital myopathy. ACTA1 heterozygous missense mutation combined with the microscopic finding of nemaline rods in the sarcoplasm warrants the diagnosis of NM in the present case. This genetic defect represents a dominant mutation arising de novo as neither parent carried the mutation. This pattern of inheritance is commonly identified in NM cases caused by the mutation in ACTA1 [4,10,11].

Due to the absence of spontaneous neonatal movement, respiratory insufficiency and fractures of both humeri and femurs at birth, NM in this patient was categorized as the severe congenital type [2,3]. The disease caused additional neurological deficits (absent primitive reflexes, loose anal sphincter tone and areflexia of all extremities). The affected diaphragm, confirmed by the presence of numerous nemaline rods, resulted in the ventilator-dependency from birth. This respiratory insufficiency was well correlated with the study data of Ryan MM and colleagues [3] in that all 23 reviewed cases with severe congenital NM had significant respiratory problems and twelve were ventilator-dependent.

Pulmonary pathology consisted of diffuse bilateral pulmonary lymphangiectasia. Absent clinical signs and symptoms of heart failure and passive congestion of liver and spleen supported the diagnosis of primary or congenital pulmonary lymphangiectasia (PPL). PPL is a rare congenital disease of unknown cause characterized by abnormal pulmonary lymphatic dilatation in the absence of secondary lymphatic obstruction [12]. Bilateral chylothorax had been clinically observed in the present case. Chylothorax is defined as the accumulation of lymphatic fluid in the pleural space. In neonatal chylothorax both congenital and traumatic (especially after thoracic surgery) forms have been recognized. Congenital chylothorax in some cases is associated with Turner syndrome, Noonan syndrome, Down syndrome, congenital lymphangiectasia

Table 1 Clinical data of case reports of congenital myopathy with chylothorax

\begin{tabular}{|c|c|c|c|c|c|}
\hline Study & Authors' study & $\begin{array}{l}\text { Garcia-Angarita, et al. } \\
(2009) \text { [7] }\end{array}$ & $\begin{array}{l}\text { Schröder, et al. } \\
(2004) \text { [6] }\end{array}$ & $\begin{array}{l}\text { Smets (2008) } \\
{[15]}\end{array}$ & $\begin{array}{l}\text { Son, et al. } \\
(2012)[16]\end{array}$ \\
\hline Age at presentation & At birth (GA 37 week) & At birth (GA 39 week) & At birth & At birth & $\begin{array}{l}\text { At birth, (GA } 30 \text { week, } \\
\text { non-identical twin A) }\end{array}$ \\
\hline Sex & Male & Male & Male & Male & Male \\
\hline Race & Thai & German & Turkish & Turkish & Korean \\
\hline Diagnosis & $\begin{array}{l}\text { Nemaline myopathy, } \\
\text { severe congenital }\end{array}$ & $\begin{array}{l}\text { Nemaline myopathy, } \\
\text { severe congenital }\end{array}$ & $\begin{array}{l}\text { Nemaline } \\
\text { myopathy } \\
\text { (intranuclear rod } \\
\text { variant), severe } \\
\text { congenital }\end{array}$ & $\begin{array}{l}\text { Myotubular } \\
\text { myopathy, } \\
\text { severe } \\
\text { congenital }\end{array}$ & $\begin{array}{l}\text { Congenital myotonic } \\
\text { dystrophy type } 1\end{array}$ \\
\hline Gene muatation & $\begin{array}{l}\text { ACTA1 gene (c.1127G > C, } \\
\text { exon 7), heterozygous }\end{array}$ & $\begin{array}{l}\text { ACTA1 gene (c.222G > T } \\
\text { \& c.223C > T, exon 3), } \\
\text { heterozygous }\end{array}$ & $\begin{array}{l}\text { ACTA1 gene } \\
\text { (Asp154Asn, exon } \\
\text { 4), heterozygous }\end{array}$ & $\begin{array}{l}\text { MTM1 gene } \\
(\text { c.1261-10A > G) }\end{array}$ & $\begin{array}{l}\text { DMPK gene (more than } \\
750 \text { CTG repeats) }\end{array}$ \\
\hline Inheritance & De novo & De novo & De novo & $\begin{array}{l}\text { X-linked } \\
\text { recessive }\end{array}$ & $\begin{array}{l}\text { Autosomal dominant } \\
\text { (affected mother) }\end{array}$ \\
\hline Chylothorax & Bilateral & Bilateral & Present & Bilateral & Bilateral \\
\hline $\begin{array}{l}\text { Triglyceride level in } \\
\text { pleural effusion (mg/dl) }\end{array}$ & 4773 & NA & NA & 746 & 495 \\
\hline Cause of chylothorax & $\begin{array}{l}\text { Primary pulmonary } \\
\text { lymphangiectasia }\end{array}$ & Not defined & Not defined & Not defined & Not defined \\
\hline $\begin{array}{l}\text { Serum creatine kinase } \\
(\mathrm{U} / \mathrm{L})\end{array}$ & $\begin{array}{l}\text { 16-25, Low, } \\
\text { (normal 30-200 U/L) }\end{array}$ & Normal & NA & NA & 281 \\
\hline Signs and symptoms & $\begin{array}{l}\text { Absent spontaneous neonatal } \\
\text { movement, respiratory } \\
\text { difficulty, fractures of both } \\
\text { humeri and femurs, high arch } \\
\text { palate }\end{array}$ & $\begin{array}{l}\text { Absent spontaneous } \\
\text { neonatal movement, } \\
\text { respiratory difficulty, } \\
\text { fractures of both humeri } \\
\text { and femurs }\end{array}$ & $\begin{array}{l}\text { Generalized } \\
\text { hypotonia, } \\
\text { respiratory } \\
\text { difficulty, right } \\
\text { pulmonary } \\
\text { hypoplasia }\end{array}$ & $\begin{array}{l}\text { Generalized } \\
\text { hypotonia, } \\
\text { respiratory } \\
\text { difficulty }\end{array}$ & $\begin{array}{l}\text { Generalized hypotonia, } \\
\text { respiratory difficulty, } \\
\text { triangular face, inverted } \\
\text { v-shaped upper lip }\end{array}$ \\
\hline $\begin{array}{l}\text { Age at death, Cause of } \\
\text { death }\end{array}$ & 6 weeks, respiratory failure & $\begin{array}{l}8 \text { weeks, respiratory } \\
\text { failure }\end{array}$ & $\begin{array}{l}9 \text { weeks, } \\
\text { respiratory failure }\end{array}$ & 16 weeks, NA & $\begin{array}{l}14 \text { weeks, respiratory } \\
\text { failure and pneumonia }\end{array}$ \\
\hline
\end{tabular}

GA, gestational age; NA, not available. 
or hydrops fetalis [9]. Despite no obvious evidence of microscopic pleural rupture in this case, the most likely cause of the bilateral chylothorax was PPL. The association between PPL and congenital chylothorax had been well documented [13,14]. Neonatal onset PPL without additional anomalies is now compatible with life and has a good prognosis in the ventilator era of neonatal intensive care [12]. In this case PPL with chylothorax may have been aggravated by the hypotonic diaphragm due to NM. Prolonged intubation since birth causing compression to the thoracic duct leading to increased hydrostatic pressure in the thoracic duct and subsequent chylous leakage is another possible additional cause of chylothorax in the present case.

Our case represents the third example of severe congenital NM with chylothorax to be documented in the literature [6,7], however, the etiology of chylothorax in those two cases has yet to be established. To the best of our knowledge, severe congenital NM with PPL causing bilateral chylothrax has never been previously reported. Two further cases of congenital myopathy (myotubular myopathy, congenital myotonic dystrophy type 1) with chylothorax of unknown cause have also been reported $[15,16]$. The reported cases are summarized in Table 1. All 3 reported cases of NM with chylothorax were male with severe congenital presentation of myopathy and de novo dominant mutation in ACTA1. Among these three cases of NM with chylothorax, none survived more than 9 weeks indicating a poor prognosis in this group and suggesting that this represents a poor prognostic sign. Moreover, recognition that chylothorax can be an unusual clinical manifestation of severe congenital NM, or other myopathies, indicates that myopathy should be included in the differential diagnosis of chylothorax in the neonate.

\section{Conclusion}

We report a case of congenital nemaline myopathy presenting with classical features of the disease (fractures, respiratory insufficiency and absence of spontaneous movement at birth) combined with unusual presentation (bilateral chylothorax due to primary pulmonary lymphangiectasia). The presence of nemaline rods in the skeletal muscle biopsy examined by light and electron microscopy, and ACTA1 mutation analysis (c.1127G > C) confirmed this muscular disorder. Lung histological examination revealed diffuse dilatation of existing lymphatic vessels. Together with the absence of secondary causes, this lung pathology was diagnosed as primary pulmonary lymphangiectasia. Recognition that chylothorax can be an unusual clinical manifestation of severe congenital NM, or other myopathies, indicates that myopathy should be included in the differential diagnosis of chylothorax in the neonate.

\section{Consent}

Written informed consent was obtained from the patient's parent for publication of this case report and any accompanying images. A copy of the written consent is available for review by the Editor-in-Chief of this journal.

\section{Abbreviations \\ ACTA1: Alpha-skeletal actin gene; COX: Cytochrome oxidase; H\&E: Haematoxylin and eosin; mGt: Modified Gömöri trichrome; NADH-TR: Nicotinamide adenine dinucleotide-tetrazolium reductase; NM: Nemaline myopathy; PAS: Periodic acid-Schiff; PASD: PAS with diastase; PPL: Primary or congenital pulmonary lymphangiectasia; SDH: Succinate dehydrogenase.}

\section{Competing interests}

The authors declare no competing interests in the writing of this manuscript.

\section{Authors' contributions}

JW and CS were involved in acquisition of data and drafting the manuscript. CK was the pediatrician in charge of the present case. CS performed autopsy examination supervised by JW. JW guided the muscle diagnosis by histopathologic and electron microscopic examinations. MR reviewed lung histopathology of the present case. JW revised the manuscript critically for important intellectual content. All authors read and approved the final manuscript.

\section{Acknowledgements}

We wish to thank the patient's parents who donated their beloved son for medical academic purpose. We are grateful to Prof. Janice Holton (UCL Institute of Neurology, The National Hospital For Neurology and Neurosurgery, England) for editing the manuscript, and to Dr. Chanin Limwongse (Faculty of Medicine Siriraj Hospital, Mahidol University, Thailand) for genetic analysis. The technical assistance of Nutta Thubthong, Pavinee Rittilarp and Suda Sanpapant are greatly acknowledged.

\section{Author details}

'Department of Pathology, Faculty of Medicine Ramathibodi Hospital, Mahidol University, Bangkok 10400, Thailand. Department of Pedriatrics, Faculty of Medicine Ramathibodi Hospital, Mahidol University, Bangkok 10400, Thailand. ${ }^{3}$ Department of Anatomy, Faculty of Science, Mahidol University, Bangkok 10400, Thailand.

Received: 7 November 2014 Accepted: 7 April 2015

Published online: 16 April 2015

\section{References}

1. Shy GM, Engel WK, Somers JE, Wanko T. Nemaline myopathy. A new congenital myopathy. Brain. 1963;86:793-810.

2. Wallgren-Pettersson C, Laing NG. Report of the $70^{\text {th }}$ ENMC International Workshop: nemaline myopathy. Neuromuscul Disord. 2000;10:299-306.

3. Ryan MM, Schnell C, Strickland CD, Shield LK, Morgan G, lannaccone ST, et al. Nemaline Myopathy - A Clinical Study of 143 cases. Ann Neurol. 2001:50(3):312-20.

4. Wallgren-Pettersson C, Sewry CA, Nowak KJ, Laing NG. Nemaline myopathies. Semin Pediatr Neurol. 2011;18(4):230-8.

5. Ravenscroft G, Miyatake S, Lehtokari VL, Todd EJ, Vornanen P, Yau KS, et al. Mutations in KLHL4O are a frequent cause of severe autosomal-recessive nemaline myopathy. Am J Hum Genet. 2013;93(1):6-18.

6. Schröder JM, Durling H, Laing N. Actin myopathy with nemaline bodies, intranuclear rods, and a heterozygous mutation in ACTA1 (Asp154Asn). Acta Neuropathol. 2004;108(3):250-6.

7. Garcia-Angarita N, Kirschner J, Heiliger M, Thirion C, Walter MC, Schnittfeld-Acarlioglu $\mathrm{S}$, et al. Severe nemaline myopathy associated with consecutive mutations E74D and H75Y on a single ACTA1 allele. Neuromuscul Disord. 2009;19(7):481-4.

8. McGrath EE, Blades Z, Anderson PB. Chylothorax: Aetiology, diagnosis and therapeutic options. Respir Med. 2010;104:1-8.

9. Van Straaten HL, Geralds $L$, Krediet TG. Chylothorax in the neonatal period. Eur J Pediatr. 1993;152(1):2-5.

10. Agrawal PB, Strickland CD, Midgett C, Morales A, Newburger DE, Poulos MA, et al. Heterogeneity of nemaline myopathy cases with skeletal muscle alpha-actin gene mutations. Ann Neurol. 2004;56(1):86-96. 
11. Wallgren-Pettersson C, Pelin K, Nowak KJ, Muntoni F, Romero NB, Goebel $\mathrm{HH}$, et al. Genotype-phenotype correlations in nemaline myopathy caused by mutations in the genes for nebulin and skeletal muscle a-actin. Neuromuscul Disord. 2004;14(8-9):461-70.

12. Barker PM, Esther Jr CR, Fordham LA, Maygarden SJ, Funkhouser WK. Primary pulmonary lymphangiectasia in infancy and childhood. Eur Respir J. 2004;24(3):413-9.

13. Lee SY, Yang SR, Lee KR. Congenital pulmonary lymphangiectasia with chylothorax. Asian Cardiovasc Thorac Ann. 2002;10(1):76-7.

14. Moerman $P$, Vandenberghe $K$, Devlieger $H$, Van Hole C, Fryns JP, Lauweryns $J M$. Congenital pulmonary lymphangiectasis with chylothorax: a heterogeneous lymphatic vessel abnormality. Am J Med Genet. 1993;47(1):54-8.

15. Smets K. X-linked myotubular myopathy and chylothorax. Neuromuscul Disord. 2008;18(2):183-4.

16. Son SB, Chun JM, Kim KA, Ko SY, Lee YK, Shin SM. A case report on 30-week premature twin babies with congenital myotonic dystrophy conceived by in vitro fertilization. J Korean Med Sci. 2012;27(10):1269-72.

\section{Submit your next manuscript to BioMed Central and take full advantage of:}

- Convenient online submission

- Thorough peer review

- No space constraints or color figure charges

- Immediate publication on acceptance

- Inclusion in PubMed, CAS, Scopus and Google Scholar

- Research which is freely available for redistribution 